\title{
Construction of a Fundamental Quantitative Evaluation Model of the A-Share Listed Companies Based on the BP Neural Network
}

\author{
Yankai Sheng $(\mathbb{D}$, Kui Fu $(\mathbb{D}$, and Jing Liang $(\mathbb{D}$ \\ School of Economics, Wuhan University of Technology, Wuhan 430070, China \\ Correspondence should be addressed to Yankai Sheng; 298671@whut.edu.cn
}

Received 6 January 2022; Revised 1 February 2022; Accepted 7 February 2022; Published 1 March 2022

Academic Editor: Shahid Mumtaz

Copyright (C) 2022 Yankai Sheng et al. This is an open access article distributed under the Creative Commons Attribution License, which permits unrestricted use, distribution, and reproduction in any medium, provided the original work is properly cited.

\begin{abstract}
Quantitative investment has attracted much attention, along with the vigorous development of Fintech. Fundamentals are one of the most important reference factors for investment. Before quantitative trading, evaluation of fundamentals may have been more dependent on personal experience. While artificial intelligence evaluation models can provide good investment suggestions and select stocks with better fundamentals. From the four angles of solvency, growth ability, operation ability, and profitability, this research selects 13 financial indicators to build a fundamental evaluation system through correlation coefficient analysis. The corporate life cycle assessment indicator is innovatively added so that the fundamental improvement expectation is put into the evaluation system. Four different kinds of scoring methods are applied to obtain a more rational and comprehensive evaluation of indicators. Then, grey relational analysis is adopted to determine the initial weight to calculate the expected output. Finally, BP neural network (back propagation) is used for training and testing to realize weight optimization. It is concluded that the model is suitable for quantitative scoring of the fundamentals of listed companies and can effectively reflect their value of them.
\end{abstract}

\section{Introduction}

Since Benjamin Graham founded the theory of value investment [1], the fundamentals of stocks have become an indispensable factor of investment. A large number of econometric models used to evaluate the intrinsic value of companies have emerged, such as Tobin's $Q$ theory $[2,3]$ and five-factor asset pricing model [4], which pushed the development of value investment. However, traditional econometric models are limited due to a lack of proof to demonstrate that the result is optimal.

With the blossom of FinTech and quantitative investment, artificial intelligence algorithms are widely used to optimize the results of traditional models and construct better portfolios. For example, a classifier model called SVM (support vector machines) has been shown to perform well in stock price forecasting [5] and financial distress [6].
Moreover, researchers have conducted a vast investigation on artificial neural networks used in the financial field such as BP (back propagation) neural network [7], LSTM (long short-term memory) neural network [8], and NARX (nonlinear autoregression exogenous) neural network [9].

Motivated by the above observations, this paper focuses on the construction of a fundamental quantitative evaluation model of the A-share listed companies based on the BP neural network. In section 2, the theoretical basis of the model is provided, in order to explain the background concepts and related technologies. In section 3, this paper provides the detailed process of model construction, including the determination of expected output and parameter setting. In section 4 , the results of the model are analyzed. In section 5, the conclusion and outlook are summarized.

The contribution of this research can be concluded as follows: 
(1) When the indicator is under a dimensionless process, a variety of evaluation methods are innovatively combined, so that the indicator score is more reasonable and comprehensive.

(2) With the corporate life cycle evaluation indicator added, the companies with fundamental improvement expectations can be identified. Since the cash flow statement is included in the evaluation system, all the important data from the three statements are included in the evaluation model for the first time.

(3) Grey relational analysis and BP neural network training simulation are used to optimize the weight of indicators so as to obtain the fundamental scoring system of all-industry listed companies.

\section{Theoretical Basis of Model Construction}

2.1. Grey Relational Analysis. Grey relational analysis is a quantitative description and comparison of the development state of objects so as to analyze and determine the influence degree between the contribution measure of factors on the main behavior. The Grey correlation degree is a measure of the correlation between two systems. If the relative change situation of the two factors is consistent in the development process, the grey correlation degree of the two factors is large; otherwise, it is small. Grey relational analysis is usually used to address the comprehensive evaluation problem [10]. Chen et al. [11] evaluated the growth of small and mediumsized listed companies through grey relational analysis, and concluded that the obtained information can be fully used with this method; Zhang et al. [12] established a quantitative evaluation model of strategic emerging industries through grey relational analysis, which made the evaluation system more reasonable; Delcea et al. [13] put forward suggestions on corporate development and extreme situation response by using the quantitative results obtained with grey relational analysis. Therefore, it is concluded that grey relational analysis is suitable for quantitative scoring of the fundamentals of listed companies, and it is reasonable to take it as the expected output of the BP neural network. The progress of grey relational analysis is shown as follows:

Step1 : The data after standardization is used to gain the grey correlation degree coefficients $\zeta_{i}(k)$ of the reference series and comparison series with formula (1).

$$
\zeta_{i}(k)=\frac{\min _{i} \min _{k}\left|g_{0}(k)-g_{i}(k)\right|+\rho \max _{i} \max _{k}\left|g_{0}(k)-g_{i}(k)\right|}{\left|g_{0}(k)-g_{i}(k)\right|+\rho \max _{i} \max _{k}\left|g_{0}(k)-g_{i}(k)\right|} .
$$

In formula (1), $g_{i}(k)$ is the score of indicators of listed companies and $\rho$ is the resolution coefficient. The usual practice is adopted in this paper where $\rho=0.5$.

Step2 : When the calculated grey relational degree coefficient is obtained, the weight calculation formula is used to obtain the weight of the indicators.

$$
\omega_{i}=\frac{\sum_{k=1}^{n} g_{i}(k)}{\sum_{k=1}^{n} \sum_{i=1}^{m} g_{i}(k)}
$$

In formula (2), $n$ is the number of sample companies and $m$ is the number of selected indicators.

Step3 : According to the weights gained, the scores of listed companies are calculated by formula (3) as the expected output of the neural network model.

$$
G(k)=\sum_{i=1}^{m} \omega_{i} \cdot g_{i}(k)
$$

In the formula, $G(k)$ means the score of the company.

2.2. BP Neural Network. The BP (back propagation) neural network, proposed by scientists led by Rumelhart and McClelland in 1986, is a gradient descent method, being able to optimize the weight and threshold through error[14]. Zhang Xuemin et al. [15] have combined an analytic hierarchy process and BP neural network to build an early warning evaluation system in order to keep poverty-stricken people from returning to poverty in specific areas; Zhang Zhengang et al. [16] used information entropy theory to determine the index weight and then used BP neural network training and simulation to construct the performance evaluation system of listed white household appliances companies in China. Thanks to its advantages in weight optimization, the BP neural network can be effectively applied to the weight selection of the quantitative evaluation system constructed in this paper. The structure of the BP neural network is shown in Figure 1.

$$
\begin{gathered}
\Delta w_{i j}=-\eta \frac{\partial \text { Error }}{\partial w_{i j}} \mathrm{i}=1,2, \ldots, \mathrm{m}, \mathrm{j}=1,2, \ldots, \mathrm{n} . \\
\Delta v_{j k}=-\eta \frac{\partial \text { Error }}{\partial v_{j k}} \mathrm{k}=1,2, \ldots, \mathrm{n}, \mathrm{j}=1,2, \ldots, \mathrm{n} .
\end{gathered}
$$

A routine $\mathrm{BP}$ neural network has 3 layers: input layer, hidden layer, and output layer. In Figure 1, $x$ is the input data, and $y$ is the output data. Assume the weight of neurons in the hidden layer is $w$, and the weight of neurons in the output layer is $v$. Assume $d$ is the expected output, then the error of the model Error can be defined by formula (4) as follows:

$$
\text { Error }=\frac{1}{2} \sum_{k=1}^{n}\left(d_{k}-y_{k}\right)^{2}
$$

In formula (4), $y_{k}$ can be denoted by formula (5), where $f$ is the activation function.

$$
y_{k}=f\left(\sum_{j=1}^{n} v_{j k} f\left(\sum_{i=1}^{m} w_{i j} x_{i}\right)\right) \text {. }
$$

If Error does not reach the target, the neural network will adjust $w$ and $v$. The adjustment amount $\Delta w_{i j}$ and $\Delta v_{j k}$ are 


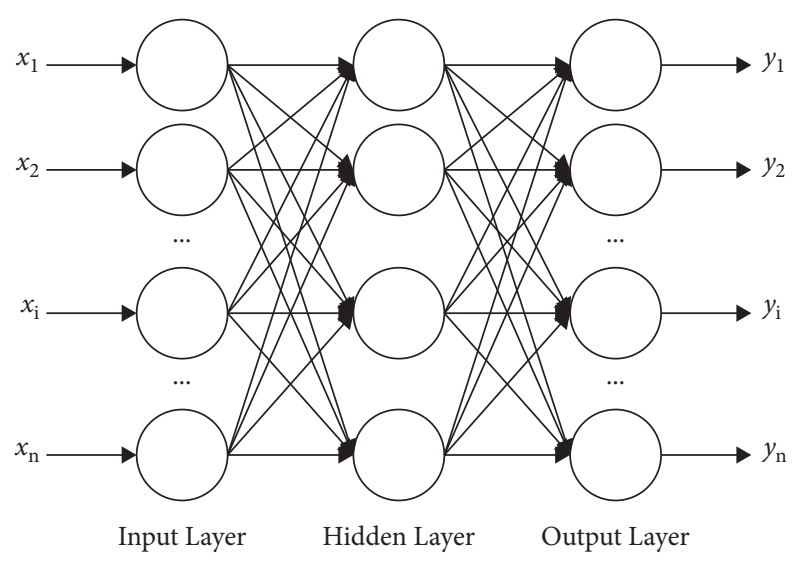

FIgURE 1: The structure of the BP neural network.

defined by formula (6) and formula (7), where $\eta$ is learning rate.

After the neural network calculates for a certain time until the Error reaches the target, the iteration will stop.

2.3. Corporate Life Cycle Theory. As early as the 1950s, Mason et al. [17] put forward that the development stage of a company can be viewed from the perspective of its life cycle. Since then, researchers have proposed a large number of life cycle stage division models, which are mainly based on the accounting indicators related to corporate organizational behavior and corporate value, where the life stages of a company are divided into segments from 3 to 10 [18]. The purpose of this paper is to establish a quantitative model so as to find a suitable method from the perspective of corporate accounting indicators. Ye [19] has put forward a revised model of the corporate life cycle based on sales and divided the corporate development into four stages. Zhang et al. [20] used the main business income growth rate, retained yield, capital expenditure rate, corporate age, and other indicators to divide the corporate life cycle and analyze its impact on the overinvestment of the company. Cao et al. [21] divided the corporate development stages into the initial stage, growth stage, maturity stage, and recession stage with the method of combination of cash flow components and discussed the corporate financial distress in different development stages, respectively.
Being the most widely used method, the cash flow combination method divides the development of companies into four stages: the start-up stage, the growth stage, the mature stage, and the recession stage, which is the method used in this paper. The division is based on Table 1 .

\section{Model Construction}

3.1. Selection of Indicators. Referring to the research of Yao Hui and Zhang Hu et al. [20,21,22], 14 indicators are selected for analysis from four dimensions as shown in Table 2: solvency, growth ability, operation ability, and profitability, as well as corporate life cycle judgment.

3.2. Selection of Evaluation Methods. According to the characteristics of different indicators, different evaluation methods are selected to turn raw data into a dimensionless score.

3.2.1. Standardized Evaluation. The indicators are standardized by formula (8) to map the data to the interval of [0, 100] to complete the scoring of a single index directly. Standardization evaluation consists of forward standardization evaluation and inverse standardization evaluation, shown as follows:

$$
\begin{aligned}
& g=\frac{x-\min (X)}{\max (X)-\min (X)} \times 100(\text { forward standardization evaluation) } \\
& g=\frac{\max (X)-x}{\max (X)-\min (X)} \times 100 \text { (inverse standardization evaluation) }
\end{aligned}
$$

In formula (8), $\mathrm{x}$ represents the original indicator data, $\mathrm{g}$ means the indicator score calculated after standardization, and $\mathrm{X}$ is the dataset of the indicators of all listed companies. Standardized evaluation retains the relationship of the original data and makes it dimensionless. Forward standardization is suitable for dealing with the indicators of "the bigger the better," while inverse standardization is suitable for the opposite [23]. 
TABLE 1: Corporate life cycle judgment by the combination of cash flow components.

\begin{tabular}{lccccc}
\hline & Start-up & Growth & Mature & \multicolumn{2}{c}{ Recession } \\
\hline Net cash flow from operating activities & - & + & + & - & + \\
Net cash flow from investment activities & - & - & - & - & + \\
Net cash flow from financing activities & + & + & - & - & + \\
\hline
\end{tabular}

TABLE 2: Selection of indicators.

\begin{tabular}{lccc}
\hline Level 1 indicator & Level 2 indicator & Evaluation method \\
\hline & Asset-liability ratio & Symbol \\
Solvency & Current ratio & Moderate analysis method evaluation \\
& Quick ratio & Forward standardization evaluation & X2 \\
& Cash flow ratio & Forward standardization evaluation \\
Growth ability & Growth rate of operating income & Forward standardization evaluation & X4 \\
& Growth rate of net profit & Ranking method evaluation & Ranking method evaluation \\
Operation ability & Inventory turnover rate & Forward standardization evaluation & X6 \\
& Turnover rate of accounts receivable & Forward standardization evaluation & X8 \\
& Turnover rate of total assets & Forward standardization evaluation & X9 \\
Profitability & Return on net assets & Forward standardization evaluation \\
& Net profit rate of sales & Forward standardization evaluation & X11 \\
Periodic judgment & Expense rate during sales period & Inverse standardization evaluation & X12 \\
& Operating cost rate & Inverse standardization evaluation & X13 \\
\hline
\end{tabular}

3.2.2. Evaluation with Ranking Method. Considering the growth rate of operating income and net profit, the measurement standard should not be "the bigger the better." For mature companies, their financial situation may be healthy, but the growth rate of operating income and net profit is relatively low compared with those companies in a growth period. Therefore, the ranking method is adopted in this research. By sorting these two indicators, the first place in the ranking is assigned 100 points, the last place in the ranking is assigned 0 points, and the middle-level companies are assigned equal and decreasing points so as to partially offset the phenomenon that the scores are too low or too concentrated caused by individual outliers [24]. The scoring criteria are shown in the following formula.

$$
g_{\text {rank }}=100-\frac{100}{n} \cdot(\operatorname{rank}-1) \text {. }
$$

In formula (9), $g_{\text {rank }}$ is the score after the ranking method, $n$ is the total number of samples, and rank is the indicator ranking.

3.2.3. Evaluation by Moderate Analysis Method. Because companies need to ensure the appropriate ratio of assets and liabilities to cope with the debt repayment crisis and a certain leverage ratio to help themselves develop, the asset-liability ratio is generally considered to be more appropriate in the interval of (50\% to $60 \%)$. Outside the interval, the more it deviates from the interval, the lower the score. The scoring criteria are shown in the following formula.

$$
g_{l e v}= \begin{cases}100, & 50 \% \leq \text { lev } \leq 60 \% \\ 100-5 \cdot(\text { lev }-60 \%) \times 100, & 60 \% \leq \text { lev } \leq 80 \% \\ 100-5 \cdot(50 \%-l e v) \times 100, & 30 \% \leq \text { lev } \leq 50 \% \\ 0, & \text { lev }<30 \% \text { or lev }>80 \%\end{cases}
$$

In formula (10), $\mathrm{g}_{\text {lev }}$ is the score of asset-liability ratio and lev is the asset-liability ratio of the company.

3.2.4. Life Cycle Assessment. Listed companies have generally passed the start-up period. Because companies often adopt the expansion strategy in the growth period, their market share normally increases rapidly, and their organizational structure would be constantly improved [25], where the fundamental improvement expectation would be the highest. However, after the listed companies enter the mature stage, their market shares tend to be saturated, their organizational structure gradually matures, and their business activities remain in a stable stage [26]. At this time, the fundamentals of companies have entered a stable stage, and the expectation of their improvement is relatively weak. When companies run into a recession, their market share will be greatly reduced, their organizational structure will be redundant, and their fundamentals will gradually deteriorate. It can also be found that the allocation of fund companies is more inclined to companies in a growth stage. According to the cash flow portfolio method, the allocation ratios of Huaxia fund in the growth stage, mature stage, and 
recession stage are $54.41 \%, 28 \%$, and $4.41 \%$, respectively, which is similar to those of other fund companies [27]. Therefore, the expected fundamental improvement brought by the corporate life cycle is scored according to formula (11).

$$
g_{T}=\left\{\begin{array}{l}
100, \text { Growth Stage } \\
80, \text { Mature Stage } \\
60, \text { Recession Stage }
\end{array}\right.
$$

In formula (11), $g_{T}$ is the score given to the company according to the corporate life cycle theory.

3.3. Index Weight Calculation. In this paper, the annual report data of listed companies in 2020 are exported through Oriental Fortune Choice financial terminal, and some outliers are eliminated, where 3,096 samples are eventually obtained.

Then, through the correlation coefficient formula (12), the correlation degree between the indicators is calculated. If the indicator correlation degree $|\rho|>0.8$, then it is eliminated. Table 3 shows the calculation result of the correlation coefficient of the indicators.

$$
\left|\rho_{i j}\right|=\left|\frac{\operatorname{COV}\left(X_{i}, X_{j}\right)}{\sqrt{D\left(X_{i}\right) D\left(X_{j}\right)}}\right|, i=1 \ldots 13, j=1 \ldots 13
$$

As can be seen from the above table, the correlation between index X2 and index X9 is relatively high, the relatively rarely used total asset turnover rate (X9) is eliminated, and the current ratio (X2) is kept.

In the following part, the grey relational analysis will be adopted to calculate the initial weight and the expected output of the BP (back propagation) neural network.

Through the whole process of grey relational analysis shown in formulas (1) and (2), the results of the weight of each indicator are shown in Table 4 . Using the weight and formula (3), the expected output can be obtained.

\subsection{Construction of BP Neural Network}

3.4.1. Input Layer Neuron. According to Table 3, $13 \mathrm{sec}-$ ondary indicators such as asset-liability ratio, the growth rate of operating income, inventory turnover rate, and return on net assets are selected as input layer neurons based on the four dimensions of solvency, growth ability, operation ability, and profitability.

3.4.2. Hidden Layer Neuron. The value range of the hidden layer node is calculated according to the empirical formula:

$$
h=\sqrt{p+q}+a, a \in[1,10] .
$$

In formula (13), $h$ represents the number of hidden layer nodes, $p$ is the number of input layer neurons, and $q$ is the number of output layer neurons. In this research, $p=13$ and $q=1$. The number of neurons of the hidden layer can be obtained in the range of $[3,13]$.

3.4.3. Output Layer Neuron. The number of output layer neurons is 1 , which outputs the fundamental scores of listed companies with a value range of $[0,100]$. The higher the output score, the better the fundamentals of the company.

Determination of initial values of weights and thresholds. In order to improve the learning speed of neural networks, the weights are set within the range of $[0,1]$ according to the usual practice, and random numbers in the range of $[0,1]$ are used as initial values of weights and thresholds.

3.5. Network Model Training. In the abovementioned 3,096 samples, 2,168 samples are randomly selected as training samples, which are recorded as $\operatorname{TR}_{\mathbf{i}}(i=1,2, \ldots, 2168)$, and the predicted value is obtained.

Since the number of neurons of the hidden layer is in a certain interval, comparative experiments are conducted in order to optimize the parameter to obtain the smallest error. The results are shown in Figure 2.

From the figure, the conclusion is obvious that the smallest error can be gained when the number of neurons of the hidden layer is 10 . Thus, the BP neural network designed in this paper sets the number of neurons in the input layer, hidden layer, and output layer as 13,10, and 1, respectively. The structure of the BP neural network is shown in Figure 3. After 1000 times of training, the error is reduced to $1.01 \times 10^{-10}$. According to the error trend chart in Figure 4, a quantitative evaluation model of the fundamentals of A-share listed companies in all industries.

A model based on BP neural network is established, and part of the training results of the BP neural network is shown in Table 5.

3.6. Simulation Result Analysis. It is necessary to test the network model in order to verify whether the BP neural network model is of the generalization ability. 604 samples are randomly selected from the remaining 1,208 samples and recorded as $\mathrm{TE}_{j}(j=1,2, \ldots, 604)$ for testing, and the test results are shown in Table 6 . The error distribution between training results and test results is shown in Figure 3.

According to Figure 5, the absolute errors of the training set and test set are mostly distributed in the interval of $\left[-1.3 \times 10^{-5}, 9.6 \times 10^{-6}\right]$, where the errors are extremely small. Therefore, the BP neural network model designed in this paper is of good generalization ability and can be applied to the fundamental evaluation and analysis of A-share listed companies in all industries.

3.7. Robustness Test. In order to test the robustness of the model, this paper changes the evaluation interval of the asset-liability ratio from formula (10) to formula (14) as follows: 
TABLE 3: Calculation result of correlation coefficient of indicators.

\begin{tabular}{|c|c|c|c|c|c|c|c|c|c|c|c|c|c|c|}
\hline & $\mathrm{X} 1$ & $\mathrm{X} 2$ & $\mathrm{X} 3$ & $\mathrm{X} 4$ & X5 & X6 & $\mathrm{X} 7$ & $\mathrm{X} 8$ & X9 & $\mathrm{X} 10$ & $\mathrm{X} 11$ & $\mathrm{X} 12$ & $\mathrm{X} 13$ & X14 \\
\hline $\mathrm{X} 1$ & 1.000 & 0.461 & 0.138 & 0.111 & 0.058 & 0.033 & 0.070 & 0.004 & 0.444 & 0.002 & 0.206 & 0.180 & 0.021 & 0.027 \\
\hline $\mathrm{X} 2$ & 0.461 & 1.000 & 0.176 & 0.080 & 0.043 & 0.031 & 0.018 & 0.064 & 0.947 & 0.041 & 0.277 & 0.354 & 0.062 & 0.012 \\
\hline $\mathrm{X} 3$ & 0.138 & 0.176 & 1.000 & 0.038 & 0.222 & 0.244 & 0.094 & 0.022 & 0.160 & 0.577 & 0.389 & 0.157 & 0.307 & 0.075 \\
\hline $\mathrm{X} 4$ & 0.111 & 0.080 & 0.038 & 1.000 & 0.238 & 0.145 & 0.361 & 0.312 & 0.064 & 0.195 & .218 & 0.070 & 0.279 & 0.049 \\
\hline X5 & 0.058 & 0.043 & 0.222 & 0.238 & 1.000 & 0.479 & 0.061 & 0.097 & 0.047 & 0.178 & 0.086 & 0.083 & 0.241 & 0.020 \\
\hline X6 & 0.033 & 0.031 & 0.244 & 0.145 & 0.479 & 1.000 & 0.027 & 0.054 & 0.035 & 0.247 & 0.105 & 0.084 & 0.127 & 0.012 \\
\hline X7 & 0.070 & 0.018 & 0.094 & 0.361 & 0.061 & 0.027 & 1.000 & 0.212 & 0.075 & 0.012 & 0.209 & 0.011 & 0.101 & 0.044 \\
\hline X8 & 0.004 & 0.064 & 0.022 & 0.312 & 0.097 & 0.054 & 0.212 & 1.000 & 0.050 & 0.075 & 0.086 & 0.146 & 0.055 & 0.053 \\
\hline X9 & 0.444 & 0.947 & 0.160 & 0.064 & 0.047 & 0.035 & 0.075 & 0.050 & 1.000 & 0.027 & 0.263 & 0.358 & 0.059 & 0.005 \\
\hline X10 & 0.002 & 0.041 & 0.577 & 0.195 & 0.178 & 0.247 & 0.012 & 0.075 & 0.027 & 1.000 & 0.192 & 0.092 & 0.286 & 0.082 \\
\hline $\mathrm{X} 11$ & 0.206 & 0.277 & 0.389 & 0.218 & 0.086 & 0.105 & 0.209 & 0.086 & 0.263 & 0.192 & 1.000 & 0.238 & 0.320 & 0.016 \\
\hline $\mathrm{X} 12$ & 0.180 & 0.354 & 0.157 & 0.070 & 0.083 & 0.084 & 0.011 & 0.146 & 0.358 & 0.092 & 0.238 & 1.000 & 0.016 & 0.138 \\
\hline $\mathrm{X} 13$ & 0.021 & 0.062 & 0.307 & 0.279 & 0.241 & 0.127 & 0.101 & 0.055 & 0.059 & 0.286 & 0.320 & 0.016 & 1.000 & 0.050 \\
\hline X14 & 0.027 & 0.012 & 0.075 & 0.049 & 0.020 & 0.012 & 0.044 & 0.053 & 0.005 & 0.082 & 0.016 & 0.138 & 0.050 & 1.000 \\
\hline
\end{tabular}

TABLE 4: Calculation results of the weight of each indicator.

\begin{tabular}{lccc}
\hline Level 1 indicator & Level 2 indicator & Symbol & Initial weight \\
\hline & Asset-liability ratio & X1 & 6.79241 \\
Solvency & Current ratio & X2 & 7.08412 \\
& Quick ratio & X3 & 8.28635 \\
Growth ability & Cash flow ratio & X4 & 7.45493 \\
& Growth rate of operating income & X5 & 7.58143 \\
Operation ability & Growth rate of net profit & X6 & 7.61459 \\
& Inventory turnover rate & X7 & 7.04270 \\
Profitability & Turnover rate of accounts receivable & X8 & 6.98549 \\
& Return on net assets & X10 & 8.22696 \\
Periodic judgment & Net profit rate of sales & X11 & 7.75891 \\
& Expense rate during sales period & X12 & 8.09567 \\
& Operating cost rate & X13 & 8.41013 \\
\hline
\end{tabular}

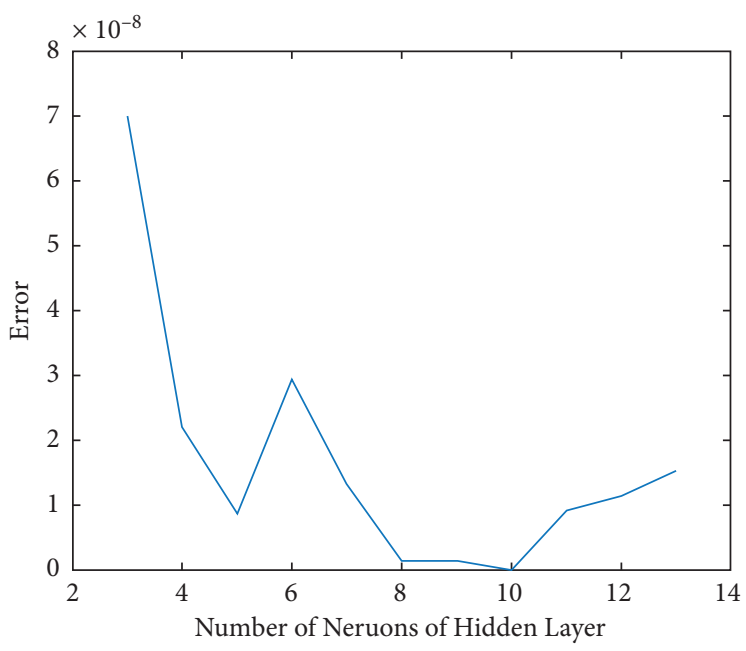

Figure 2: Contrast of error under different parameter settings. 


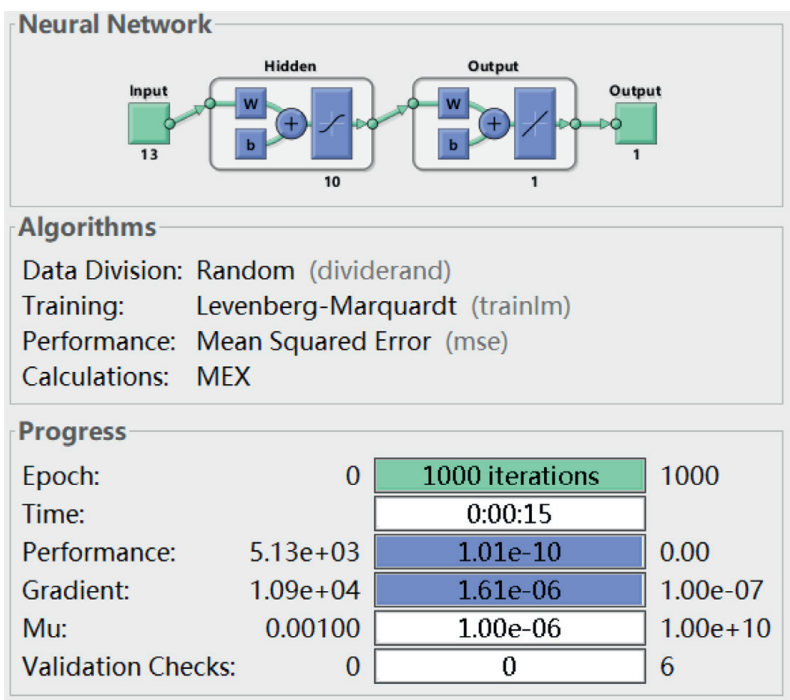

FIgURE 3: Structure diagram of BP neural network.

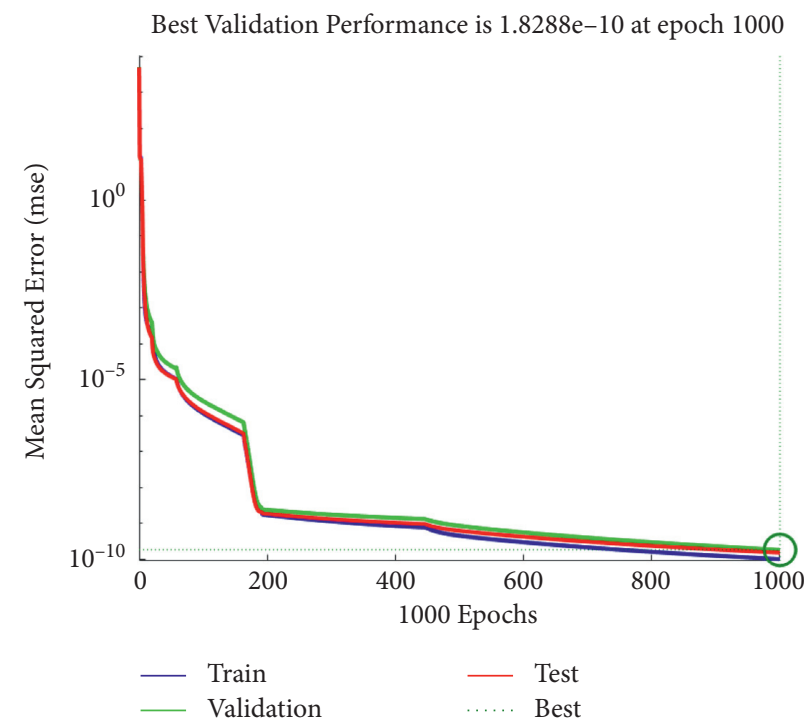

Figure 4: Training error diagram of BP neural network.

TABLE 5: Part of training results of BP neural network.

\begin{tabular}{lccc}
\hline Sample & Expected output & Actual output & Relative error (\%) \\
\hline TR1 & 53.73083 & 53.73004 & 0.00147 \\
TR2 & 50.00218 & 50.00140 & 0.00157 \\
TR3 & 46.79068 & 46.79015 & 0.00113 \\
TR4 & 51.67963 & 51.67902 & 0.00119 \\
TR5 & 33.12191 & 33.12213 & 0.00064 \\
TR6 & 49.96475 & 49.96402 & 0.00145 \\
TR7 & 53.76107 & 53.76060 & 0.00088 \\
TR8 & 42.72477 & 42.72418 & 0.00138 \\
TR9 & 44.14657 & 44.14600 & 0.00130 \\
TR10 & 51.30777 & 51.30702 & 0.00146 \\
TR11 & 47.05807 & 47.05735 & 0.00154 \\
TR12 & 38.52720 & 38.52665 & 0.00144 \\
TR13 & 49.56071 & 49.55982 & 0.00179 \\
TR14 & 55.86725 & 55.86679 & 0.00083 \\
\hline
\end{tabular}


TABle 5: Continued.

\begin{tabular}{lccc}
\hline Sample & Expected output & Actual output & Relative error (\%) \\
\hline TR15 & 48.76789 & 48.76711 & 0.00159 \\
TR16 & 35.99980 & 36.00023 & 0.00119 \\
TR17 & 61.00887 & 61.00867 & 0.00033 \\
TR18 & 54.59437 & 54.59362 & 0.00137 \\
TR19 & 48.13704 & 48.13696 & 0.00018 \\
TR20 & 57.71973 & 57.71944 & 0.00052 \\
\hline
\end{tabular}

TABLE 6: Part of test results of BP neural network.

\begin{tabular}{lccc}
\hline Sample & Expected output & Actual output & Relative error (\%) \\
\hline TE1 & 49.36534 & 49.36480 & 0.00109 \\
TE2 & 58.05768 & 58.05710 & 0.00100 \\
TE3 & 52.53170 & 52.53105 & 0.00125 \\
TE4 & 44.80344 & 44.80370 & 0.00058 \\
TE5 & 51.88164 & 51.88119 & 0.00087 \\
TE6 & 47.13900 & 47.13851 & 0.00105 \\
TE7 & 55.08644 & 55.08563 & 0.00147 \\
TE8 & 62.44150 & 62.44073 & 0.00122 \\
TE9 & 56.11946 & 56.11873 & 0.00129 \\
TE10 & 44.80488 & 44.80430 & 0.00129 \\
TE11 & 54.30785 & 54.30721 & 0.00118 \\
TE12 & 56.28334 & 56.28285 & 0.00087 \\
TE13 & 55.43343 & 55.43308 & 0.00064 \\
TE14 & 53.17385 & 53.17326 & 0.00111 \\
TE15 & 47.63893 & 47.63834 & 0.00124 \\
TE16 & 45.67614 & 45.67584 & 0.00066 \\
TE17 & 61.13550 & 61.13490 & 0.00098 \\
TE18 & 55.73245 & 55.73178 & 0.00121 \\
TE19 & 51.39826 & 51.39782 & 0.00084 \\
TE20 & 55.22763 & 55.22727 & 0.00064 \\
\hline
\end{tabular}

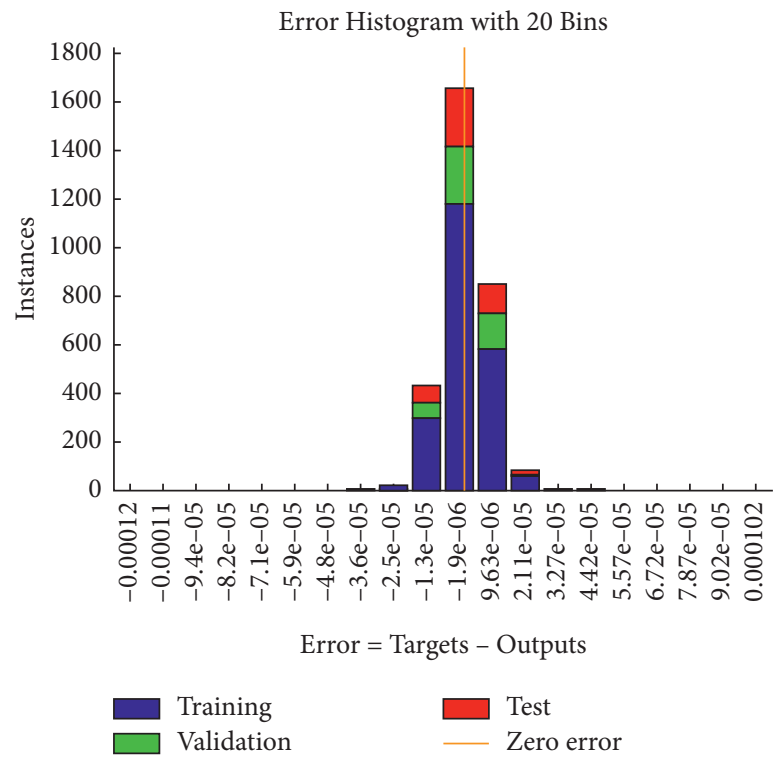

FIGURE 5: Error distribution diagram of BP neural network. 


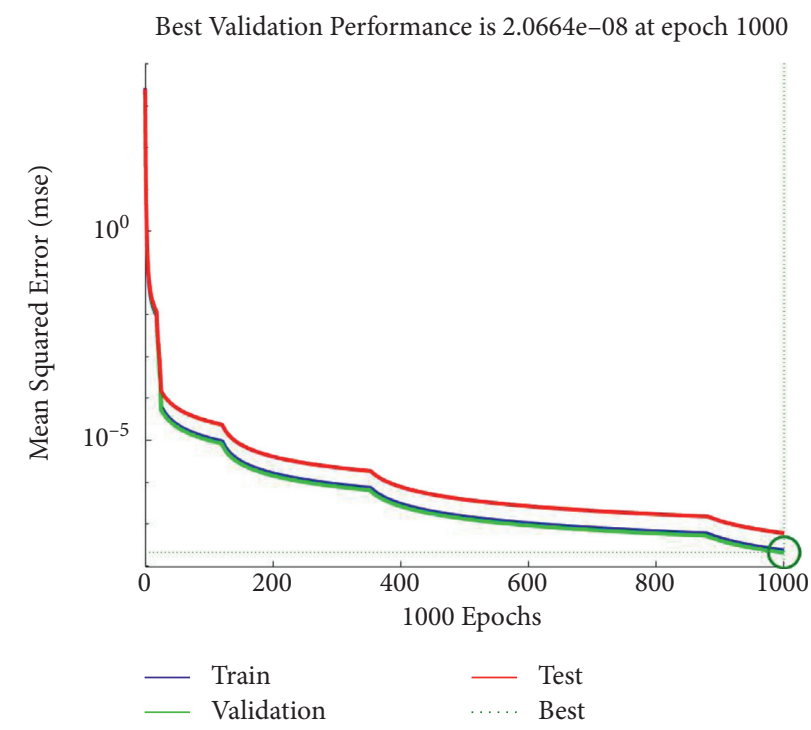

FIgURE 6: Training error diagram of robustness test.

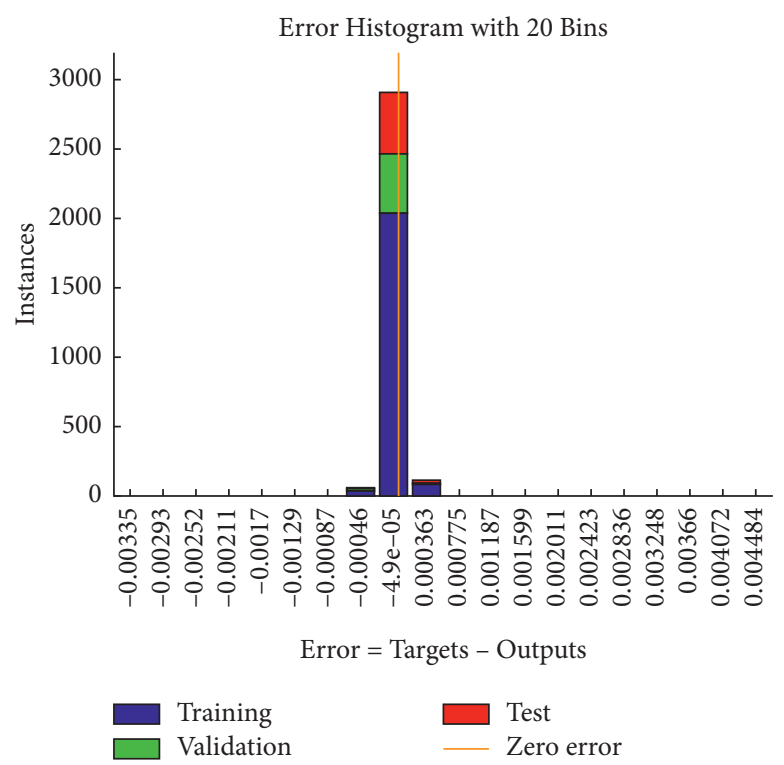

Figure 7: Error distribution diagram of robustness test.

$$
g_{l e v}= \begin{cases}100, & 45 \% \leq \text { lev } \leq 65 \% \\ 100-5 \cdot(l e v-65 \%) \times 100, & 65 \% \leq \text { lev } \leq 80 \% \\ 100-5 \cdot(45 \%-l e v) \times 100, & 30 \% \leq \text { lev } \leq 45 \% \\ 0, & \text { lev }<30 \% \text { or lev }>80 \%\end{cases}
$$

The new score is substituted into the model of the BP neural network, and the training error diagram shown in Figure 6 and the error distribution diagram shown in Figure 7 are obtained. It can be found that after 1000 iterations, the error is reduced to $2.0664 \times 10^{-8}$, and the absolute errors are mostly distributed in $\left[-4.6 \times 10^{-4}, 3.6 \times 10^{-4}\right]$. Therefore, the BP neural network model established in this paper is robust.

\section{Result Analysis}

The author calculates the initial weight of each indicator of fundamental evaluation of listed companies through grey relational analysis and optimizes the weight through BP (back propagation) neural network. According to the calculation results of the training set data, the model can be established. According to the calculation results of the test set data, it can be concluded that the model has generalization ability. With this model, the fundamentals of A-share listed companies in China can be summarized to put forward some suggestions for fundamental evaluation.

4.1. Weight Analysis. The weights optimized by the BP neural network are shown in Table 7. Among them, 
TABLE 7: Optimization results of the weight of each indicator.

\begin{tabular}{lcccc}
\hline Level 1 indicator & Level 2 indicator & Symbol & Initial weight & Optimized weight \\
\hline \multirow{4}{*}{ Solvency } & Asset-liability ratio & X1 & 6.79241 & 6.79240 \\
& Current ratio & X2 & 7.08412 & 7.08433 \\
Growth ability & Quick ratio & X3 & 8.28635 & 8.28747 \\
& Cash flow ratio & X4 & 7.45493 & 7.45499 \\
Operation ability & Growth rate of operating income & X5 & 7.58143 & 7.58136 \\
& Growth rate of net profit & X6 & 7.61459 & 7.61451 \\
& Inventory turnover rate & X7 & 7.04270 & 7.04273 \\
Profitability & Turnover rate of accounts receivable & X8 & 6.98549 & 8.98539 \\
& Return on net assets & X10 & 8.22696 & 7.22687 \\
Periodic judgment & Net profit rate of sales & X11 & 7.75891 & 8.75800 \\
& Expense rate during sales period & X12 & 8.09567 & 8.41013 \\
\end{tabular}

TABLE 8: Scores of each indicator of the 10 listed companies with the highest scores.

\begin{tabular}{lcccccccccccccc}
\hline Sample & X1 & X2 & X3 & X4 & X5 & X6 & X7 & X8 & X10 & X11 & X12 & X13 & X14 & Score \\
\hline S1 & 100.000 & 34.503 & 100.000 & 100.000 & 15.700 & 34.400 & 100.000 & 100.000 & 100.000 & 81.108 & 67.500 & 100.000 & 60.000 & 76.410 \\
S2 & 42.100 & 100.000 & 100.000 & 100.000 & 88.300 & 2.800 & 100.000 & 95.177 & 100.000 & 81.296 & 0.000 & 100.000 & 60.000 & 74.428 \\
S3 & 72.250 & 70.000 & 92.482 & 100.000 & 28.400 & 13.100 & 85.031 & 100.000 & 89.890 & 50.455 & 81.165 & 76.081 & 100.000 & 74.056 \\
S4 & 24.700 & 100.000 & 100.000 & 100.000 & 77.500 & 83.500 & 0.000 & 100.000 & 100.000 & 100.000 & 100.000 & 0.000 & 60.000 & 73.005 \\
S5 & 67.950 & 55.135 & 81.812 & 100.000 & 62.700 & 75.000 & 58.710 & 100.000 & 100.000 & 83.214 & 0.000 & 69.767 & 60.000 & 70.090 \\
S6 & 0.000 & 19.434 & 94.273 & 100.000 & 74.900 & 91.800 & 38.377 & 100.000 & 88.921 & 61.046 & 68.471 & 92.643 & 60.000 & 69.586 \\
S7 & 100.000 & 7.715 & 90.124 & 100.000 & 31.000 & 60.100 & 84.081 & 20.917 & 73.218 & 66.218 & 59.180 & 98.857 & 100.000 & 69.504 \\
S8 & 100.000 & 46.341 & 100.000 & 97.727 & 19.800 & 25.200 & 75.463 & 68.541 & 100.000 & 65.569 & 100.000 & 43.964 & 60.000 & 69.478 \\
S9 & 80.250 & 18.387 & 91.789 & 100.000 & 10.100 & 47.100 & 100.000 & 100.000 & 93.759 & 66.331 & 32.890 & 100.000 & 60.000 & 69.326 \\
S10 & 77.350 & 13.430 & 88.656 & 51.429 & 93.200 & 88.600 & 100.000 & 9.622 & 87.519 & 59.887 & 69.430 & 80.162 & 60.000 & 68.322 \\
\hline
\end{tabular}

TABle 9: Descriptive statistics of scores of all indicators.

\begin{tabular}{lccccccccccccccc}
\hline & $\mathrm{X} 1$ & $\mathrm{X} 2$ & $\mathrm{X} 3$ & $\mathrm{X} 4$ & $\mathrm{X} 5$ & $\mathrm{X} 6$ & $\mathrm{X} 7$ & $\mathrm{X} 8$ & $\mathrm{X} 10$ & $\mathrm{X} 11$ & $\mathrm{X} 12$ & $\mathrm{X} 13$ & $\mathrm{X} 14$ & Score \\
\hline Max & 0.000 & 0.000 & 0.000 & 0.000 & 0.000 & 0.000 & 0.000 & 0.000 & 0.000 & 0.000 & 0.000 & 0.000 & 60.000 & 18.372 \\
Min & 100.000 & 100.000 & 100.000 & 100.000 & 100.000 & 100.000 & 100.000 & 100.000 & 100.000 & 100.000 & 100.000 & 100.000 & 100.000 & 76.410 \\
Average & 43.854 & 22.074 & 68.523 & 30.535 & 49.972 & 49.972 & 21.364 & 20.933 & 65.064 & 47.595 & 61.820 & 74.441 & 64.289 & 48.940 \\
\hline
\end{tabular}

solvency, growth ability, operation ability, profitability, and cycle judgment account for 29.61919\%, 15.19587\%, $14.02812 \%, 32.48885 \%$, and $8.66757 \%$, respectively. Profitability accounts for the highest proportion, followed by solvency, and there is little difference between growth ability and operational ability. It can be explained that profitability reflects the income quality of listed companies and is the most important part in the fundamental evaluation of listed companies. Solvency reflects the risk control of listed companies and is therefore of great significance in fundamental evaluation.

4.2. Scoring Results Analysis. The top 10 listed companies in the scoring order are selected on the basis of the scoring results, where it can be found in Table 8 that listed companies with higher scores have higher scores in return on net assets, quick ratio, and cash flow ratio. These three indicators reflect the efficiency of shareholders' funds, the solvency and liquidity of assets. Companies with good fundamentals have certain advantages in these aspects.

According to the descriptive statistics of each indicator shown in Table 9, China's listed companies have higher average scores in operating cost ratio and quick ratio, but lower scores in inventory turnover rate and accounts receivable turnover rate, which reflects that the listed companies have relatively strong profitability and solvency, while their operational ability is relatively weak. When making a stock selection, the important indicator of operational ability can be put into consideration to see if the company is leading in the industry.

\section{Conclusion}

This paper explores the application of BP (back propagation) neural networks in fundamental evaluation. Firstly, raw data of China's listed companies are imported and standardized by different scoring methods, which ensures rationality and comprehensiveness of the original score. Secondly, grey relational analysis is conducted in order to obtain the initial weight and expected output. Then, a 3-layer BP neural network is constructed after parameter optimization. The result is tested and validated. Finally, the result was analyzed from 2 aspects: weight analysis and scoring result analysis, where relative suggestions are provided for investors. 
Based on the experiment, a BP neural network used to evaluate the fundamentals of companies of all industries was constructed. This experiment proposed a new system of evaluation methods for all indicators that uses the important financial indexes of three statements for the first time. In addition, with the use of the corporate life cycle evaluation indicator, the companies with fundamental improvement expectations can be identified, which is an innovative attempt.

Although a BP neural network model has been constructed successfully, there are still some points that need to be improved.

(1) The scores shown in Table 9 may not be rational since most of the samples seem to be in a recession stage, which disobeys common sense. Therefore, more precise algorithms should be applied to score the stage of companies.

(2) There is still room for continued optimization in the internal structure of grey relational analysis and BP neural network, which can lead to more precise results.

(3) Other advanced artificial neural networks can be used to compare with BP neural network, which is the direction of future efforts.

\section{Data Availability}

The data used to support the findings of this study are available from the corresponding author upon request.

\section{Conflicts of Interest}

The authors declare that there are no conflicts of interest.

\section{References}

[1] B. Graham and D. L. Dodd, Security Analysis [M], Whittlesey House, New York, 1934.

[2] B. Julio and Y. Yook, "Political uncertainty and corporate investment cycles [J]," The Journal of Finance, no. 67, pp. 45-83, 2012.

[3] S. Chen, Z. Sun, S. Tang, and D. Wu, "Government intervention and investment efficiency: Evidence from China [J]," Journal of Corporate Finance, vol. 17, no. 2, pp. 259-271, 2011.

[4] E. F. Fama and K. R. French, "A five-factor asset pricing model [J]," Journal of Financial Economics, vol. 116, no. 1, pp. 1-22, 2015.

[5] J. Patel, S. Shah, P. Thakkar, and K. Kotecha, "Predicting stock and stock price index movement using Trend Deterministic Data Preparation and machine learning techniques [J]," Expert Systems with Applications, vol. 42, no. 1, pp. 259-268, 2015.

[6] J. Sun, H. Li, H. Fujita, B. Fu, and W. Ai, "Class-imbalanced dynamic financial distress prediction based on AdaboostSVM ensemble combined with SMOTE and time weighting," Information Fusion, vol. 54, no. 54, pp. 128-144, 2020.

[7] X. Jin, Q. Liu, and H. Long, "Impact of cost-benefit analysis on financial benefit evaluation of investment projects under back propagation neural network [J]," Journal of Computational and Applied Mathematics, vol. 384, no. 2, p. 113172, 2021.
[8] T. Fischer and C. Krauss, "Deep learning with long short-term memory networks for financial market predictions[J]," European Journal of Operational Research, vol. 270, no. 2, pp. 654-669, 2018.

[9] A. Amo Baffour, J. Feng, and E. K. Taylor, "A hybrid artificial neural network-GJR modeling approach to forecasting currency exchange rate volatility," Neurocomputing, vol. 365, no. 365, pp. 285-301, 2019.

[10] Q. Wang and Li Cheng, "Grey relational analysis of technological innovation and economic performance of enterprises [J]," Forum on Science and Technology in China, no. 12, pp. 64-68, 2009.

[11] X. Chen, S. Jian, and X. Zou, "Comparative study on growth evaluation methods of small and medium-sized listed companies [J]," Science Research Management, no. 01, pp. 145-151, 2006.

[12] L. Zhang, Z. He, and Y. Wu, "Evaluation of strategic emerging industries based on grey relational analysis - taking biomedicine as an example [J]," Journal of Quantitative Economics, vol. 27, no. 03, pp. 79-84, 2010.

[13] C. Delcea, E. Scarlat, and L. A. Cotfas, "Companies' quality characteristics vs their performance," Grey Systems: Theory and Application, vol. 3, no. 2, pp. 129-141, 2013.

[14] S. Ding, C. Su, and J. Yu, "An optimizing BP neural network algorithm based on genetic algorithm [J]," Artificial Intelligence Review, vol. 36, pp. 153-162, 2011.

[15] X. Zhang, L. Shi, X. Yan, and L. Xinfa, "Construction and demonstration of early warning evaluation index system for keep from returning to poverty in the perspective of rural revitalization [J]," Statistics \& Decisions, vol. 37, no. 13, pp. 58-62, 2021.

[16] Z. Zhang, M. Xie, and D. Lin, "Performance evaluation system of Chinese manufacturing companies based on BP neural network - taking listed white household appliances manufacturing companies as an example [J]," Science and Technology Management Research, vol. 40, no. 15, pp. 217223, 2020.

[17] M. Haire, "Biologic models and empirical histories in the growth of organizations [A]," in Modern Organization Theory: A Symposium [M], M. Haire, Ed., John Wiley \& Sons, New York, 1959.

[18] Z. Zhu, Research on Financial Crisis Early Warning from the Perspective of Corporate Lifecycle [D], Southeast University, 2016.

[19] Li Ye, "Revised model and thinking of corporate life cycle [J]," Southern China Journal of Economics, no. 02, pp. 47-50, 2000.

[20] Hu Zhang, H. Shen, and Y. Liu, "Research on multi-factor quantitative stock selection based on self-attention neural network [J]," Journal of Applied Sport Management, vol. 39, no. 03, pp. 556-570, 2020.

[21] Yu Cao and X.-hong Chen, “An agent-based simulation model of enterprises financial distress for the enterprise of different life cycle stage [J]," Simulation Modelling Practice and Theory, vol. 20, no. 1, 2011.

[22] H. Yao and T. Wu, "An empirical study on value investingstrategy considering fundamentals and valuation indexes - empirical data from China's Shanghai and Shenzhen A-share markets from 2000 to 2013 [J]," Review of Investment Studies, vol. 33, no. 11, pp. 123-138, 2014.

[23] Y. Yang and D. Zhang, "Correlation analysis between comprehensive score and stock price based on improved Wall motion score index [J]," China Township Enterprises Accounting, no. 02, pp. 45-48, 2021. 
[24] Q. Xue and J. Zhao, "Wall motion score index and operation evaluation of enterprise productivity promotion center [J]," Journal of Shanxi University(Philosophy and Social Science Edition), vol. 37, no. 03, pp. 140-144, 2014.

[25] I. M. Jawahar and G. L. McLaughlin, "Toward a descriptive Stakeholder theory: an organizational life cycle approach," Academy of Management Review, vol. 26, no. 3, pp. 397-414, 2001.

[26] X. Cheng, Q. Wu, M. Liu, and Yu Cheng, "Cash distribution, management incentive and capital allocation efficiency of enterprise groups [J]," Journal of Financial Research, no. 02, pp. 91-108, 2020.

[27] S. Chang and S. Liu, "Research on the division and measurement of Chinese corporate life cycle stages [J]," Commercial Research, no. 01, pp. 1-10, 2011. 